\title{
Health Coaching Has Differential Effects on Veterans with Limited Health Literacy and Numeracy: a Secondary Analysis of ACTIVATE
}

\author{
Sarah S. Nouri, M.D., M.P.H. ${ }^{7}$, Laura J. Damschroder, MPH, MS ${ }^{2}$, Maren K. Olsen, PhD ${ }^{3,4,5}$, \\ Jennifer M. Gierisch, PhD, MPH ${ }^{2,4}$, Angela Fagerlin, PhD ${ }^{6,7}$, Linda L. Sanders, MPH ${ }^{3,4}$, \\ Felicia McCant, MSSW4, and Eugene Z. Oddone, M.D., M.H.Sc. ${ }^{3,4}$
}

\begin{abstract}
'Division of General Internal Medicine, Department of Medicine, University of California, San Francisco, CA, USA; ${ }^{2}$ VA Center for Clinical Management Research,VA Ann Arbor Healthcare System, Ann Arbor, MI, USA; ${ }^{3}$ Division of General Internal Medicine, Department of Medicine,Duke University Medical Center, Durham, NC, USA; ${ }^{4}$ Durham Center of Innovation to Accelerate Discovery and Practice Transformation (ADAPT),Durham VA Health Care System, Durham, NC, USA; ${ }^{5}$ Department of Biostatistics and Bioinformatics, Duke University, Durham, NC, USA; ${ }^{6}$ Salt Lake City VA Informatics Decision-Enhancement and Analytic Sciences (IDEAS 2.0) Center for Innovation, Salt Lake City, UT, USA; ${ }^{7}$ Department of Population Health Sciences, University of Utah, Salt Lake City, UT, USA.
\end{abstract}

\begin{abstract}
:
BACKGROUND: Health coaching is an effective behavior change strategy. Understanding if there is a differential impact of health coaching on patients with low health literacy has not been well investigated.

OBJECTIVE: To determine whether a telephone coaching intervention would result in similar improvements in enrollment in prevention programs and patient activation among Veterans with low versus high health literacy (specifically, reading literacy and numeracy).

DESIGN: Secondary analysis of a randomized controlled trial.

PARTICIPANTS: Four hundred seventeen Veterans with at least one modifiable risk factor: current smoker, BMI $\geq$ 30 , or $<150 \mathrm{~min}$ of moderate physical activity weekly.

METHODS: A single-item assessment of health literacy and a subjective numeracy scale were assessed at baseline. A logistic regression and general linear longitudinal models were used to examine the differential impact of the intervention compared to control on enrollment in prevention programs and changes in patient activation measures (PAM) scores among patients with low versus high health literacy.

RESULTS: The coaching intervention resulted in higher enrollment in prevention programs and improvements in PAM scores compared to usual care regardless of baseline health literacy. The coaching intervention had a greater effect on the probability of enrollment in prevention programs for patients with low numeracy (intervention vs control difference of $0.31,95 \% \mathrm{CI} 0.18,0.45$ ) as compared to those with high numeracy $(0.13,95 \% \mathrm{CI}-0.01,0.27)$; the low compared to high differential effect was clinically, but not statistically significant $(0.18,95 \% \mathrm{CI}-0.01,0.38$; $p=0.07$ ). Among patients with high numeracy, the intervention group had greater increases in PAM as compared to the control group at 6 months (mean difference in improvement $4.8 ; 95 \%$ CI 1.7, 7.9; $p=0.003$ ). This led to a clinically and statistically significant differential
\end{abstract}

Received April 29, 2018

Revised October 25, 2018

Accepted December 18, 2018

Published online February 12, 2019 intervention effect for low vs high numeracy $(-4.6$; $95 \%$ CI $-9.1,-0.15 ; p=0.04$ ).

CONCLUSIONS: We suggest that health coaching may be particularly beneficial in behavior change strategies in populations with low numeracy when interpretation of health risk information is part of the intervention.

CLINICALTRIALS.GOV IDENTIFIER: NCT01828567

KEY WORDS: telephone coaching; health risk assessment; health literacy; health numeracy.

$J$ Gen Intern Med 34(4):552-8

DOI: $10.1007 / \mathrm{s} 11606-019-04861-7$

(c) Society of General Internal Medicine 2019

\section{INTRODUCTION}

Health risk assessment and health coaching can be important elements of health promotion, a goal of which is to increase patient activation and participation in programs designed to improve health behaviors. ${ }^{1-3}$ Patients who score higher on measures of activation have been shown to have improved health outcomes, as well as increased positive behavior change. $^{2,} 4,5$ Health coaching, which combines education and motivational interviewing with problem-solving strategies and psychosocial support, has been shown to be effective as a behavior change strategy in a variety of settings, including primary care. ${ }^{3,6-10}$

Many social and health-related factors are associated with lower levels of activation and lower levels of engaging patients in healthy behaviors. ${ }^{11-13}$ Health literacy is one such factor that is critical to patient activation and patient selfadvocacy. ${ }^{14-17}$ Health literacy is defined by the Institute of Medicine as "the degree to which individuals have the capacity to obtain, process, and understand basic health information and services needed to make appropriate health decisions". ${ }^{18}$ This includes a range of literacy skills, including not only reading, but also writing, speaking and listening, and numeracy. Nearly half of American adults have limited health 
literacy, lacking the skills needed to consistently and accurately use health information. ${ }^{18-22}$

Low health literacy is more prevalent among older, minority, low socioeconomic status, and immigrant populations and has been associated with poor health outcomes, such as increased hospitalizations and use of emergency care, decreased use of preventive services, poor self-management of chronic diseases, and higher all-cause mortality. ${ }^{18,23}$ These findings persist even after controlling for potential confounders, such as sociodemographic factors and baseline physical and mental health. ${ }^{24}$ Low health numeracy specifically has been implicated in difficulties with risk communication, interpretation of health information, and decision-making. ${ }^{23,} 25$ Interestingly, health literacy has been demonstrated to mediate both racial and age-related disparities for a variety of health outcomes, ${ }^{23}$, 26, 27 and based on more recent research has emerged as an important independent predictor of health disparities. ${ }^{28-30}$ The differential impact of certain behavior change intervention strategies, including health coaching, on patients with low versus adequate health literacy has not been fully investigated.

The Evaluation of A Coaching by Telephone Intervention for Veterans and Care Team Engagement (ACTIVATE) trial assessed rates of enrollment in prevention programs and changes in behavioral activation in Veterans participating in a telephone coaching intervention. The coaching intervention tested in ACTIVATE resulted in a greater than twofold rate of enrollment in prevention services compared to controls. ${ }^{31}$ In this secondary analysis, we hypothesized that the intervention effect would be stronger among Veterans with low health literacy (specifically, reading and numeric literacy) as compared to those with high health literacy.

\section{METHODS}

\section{The ACTIVATE Trial}

The ACTIVATE trial was a randomized controlled trial evaluating enrollment in prevention programs and changes in behavioral activation in Veterans receiving a comprehensive health risk assessment and telephone coaching intervention compared to Veterans receiving health risk assessment and usual care. ${ }^{32}$ The study was conducted in three Veterans Health Administration (VHA) primary care clinics in Ann Arbor, Michigan, Durham, North Carolina, and Greenville, North Carolina; the Ann Arbor and Durham VA Medical Centers are academically-affiliated, and the Greenville VA is affiliated with the Durham VA. Eligible Veterans included those who were enrolled in primary care and had at least one modifiable risk factor: $\mathrm{BMI} \geq 30$, current smoker, and/or less than 150 min of moderate/vigorous physical activity per week. Veterans were excluded if they were diagnosed with dementia, active psychosis, serious personality disorder, current uncontrolled substance use disorder, severely impaired hearing or speech, terminal illness (with referral to hospice or palliative care); other exclusion criteria were inability to speak English, lack of access to a telephone, residence in a nursing home, or having participated in a prevention program or another VA study in the previous 6 months.

All enrolled Veterans $(n=417)$ completed the HealtheLiving Assessment at baseline, which is the VHA's web-based health risk assessment (HRA). ${ }^{33}$ The HRA, publicly available via the patient web-portal "MyHealtheVet," uses statistical risk modeling to provide patients with "health age" based on lifestyle choices, family risk, and biological values, as well as information about the degree to which lifestyle changes can lower their "health age." The intervention group received two telephone calls from a trained health coach, whereas those in the usual care control group received no telephone coaching. The first telephone call occurred 1 week after the baseline interview; during this call, health coaches worked with participants to set goals to enroll in a prevention program. The second telephone call occurred 1 month after the initial call, with the primary purpose of reviewing whether the participant had made progress towards their goal; if the participant had not yet enrolled in a prevention program, the coach worked on problem-solving and setting a new goal for enrollment. The usual care group received a printed copy of their HRA output and were encouraged to discuss questions with their primary care team; primary care teams were also notified of their patients' participation in the study via a note in the electronic medical record.

The primary outcomes were self-reported enrollment in a structured prevention program (assessed at 1 month and 6 months after baseline) and Veteran activation as measured by the Patient Activation Measure (PAM) (measured at baseline, 1 month, and 6 months after baseline). The PAM is a 13item measure that evaluates individuals' knowledge, skills, beliefs, and confidence for managing their health, and has demonstrated high construct validity. ${ }^{1,}{ }^{34}$ A 4-6 point difference on the 100-point scale has been identified as clinically meaningful. ${ }^{35}$ Results of ACTIVATE showed higher rates of enrollment in prevention programs (51 vs $29 \%, \mathrm{OR}=2.5$; $95 \%$ CI 1.7, 3.9; $p<0.0001)$ and greater mean increase in patient activation measure (PAM) scores at 6 months (mean difference $2.5 ; 95 \%$ CI $0.2,4.7 ; p=0.03$ ) in the intervention group compared to the usual care group. ${ }^{31}$

\section{Literacy and Numeracy Measures}

For the purposes of this study, we will use the term "literacy" to refer specifically to reading health literacy and "numeracy" to refer to numeric health literacy.

Baseline information was obtained from Veterans during a face to face meeting with a research assistant. Literacy was assessed using a single-item question developed by Chew et al.: "Do you usually ask someone to help you read materials you receive from the hospital?". 36 The answers were in the form of a 5-item ordinal response scale. For this study, we placed Veterans into two groups according to their responses: Veterans who reported "never" requiring assistance were classified as "high literacy" and Veterans who listed any other 
response ("rarely," "sometimes," "often," or "always") were classified as "low literacy." This measure has been validated in a large outpatient VA population against the S-TOFHLA and REALM $^{37}$ and has a sensitivity of $>90 \%$ to detect low literacy when using the cutoff point in the ordinal response scale used in this analysis. ${ }^{38}$

We used a modification of the Subjective Numeracy Scale (SNS) to assess numeracy. ${ }^{39,40}$ The modified version uses 3 of the original 8 items from the measure to evaluate numeracy: self-reported skill working with fractions, skill working with percentages, and frequency of usefulness of numerical information. The 3-item SNS has been independently validated in several large cohorts of adult patients (including Veterans) and has been demonstrated to correlate well with the full 8-item SNS (median $\rho$ 0.91) and other numeracy measures. ${ }^{41}$ The mean of the scores for the three questions was calculated and patients were split into two groups ("high numeracy" versus "low numeracy") based on their median summary scores ( minimum $=1$, maximum $=6$, mean $=4.6$, median $=4.67$ ). Scores that were on the median were included in the "low numeracy" group.

\section{Statistical Analysis}

Two separate logistic regression models were used to examine the intervention effect on enrollment in a prevention program for literacy and numeracy subgroups; one model examined the differential intervention effect for high and low literacy, and the other model examined the differential intervention effect for high and low numeracy. The outcome variable in both models was whether or not the patient enrolled in a prevention program by 6 months. Each model included indicator variables for intervention group, high literacy/numeracy, the interaction between intervention and literacy/numeracy. Finally, we used a single logistic model which included indicators for both literacy and numeracy and their interaction to investigate the possibility of an interaction effect. PROC GLM in SAS (version 9.4) was used to fit the models and generate estimated probabilities, risk differences, and corresponding 95\% confidence intervals and $p$ values.

Two separate repeated measures general linear models (PROC MIXED in SAS, version 9.4) were used to estimate mean PAM scores over time; one model examined the differential intervention effect for high and low literacy, and the other model examined the differential intervention effect for high and low numeracy. For each, the final model parameters included a common intercept for patients with limited literacy or numeracy, a common intercept for patients with adequate literacy or numeracy, dummy-coded time, an intervention arm indicator variable interacted with each follow-up time-point, and each of these terms interacted with literacy and numeracy subgroups. Again, we also used a single repeated measured model with indicators for both literacy and numeracy and their interaction to investigate the possibility of an interaction effect of the two domains on PAM scores over time. PROC MIXED in SAS (version 9.4) was used to fit the models and test for PAM differences at 6 weeks and 6 months. An unstructured covariance was included to account for patients' repeated measurements over time.

\section{RESULTS}

Tables 1 and 2 show baseline characteristics of the study subjects according to those with high and low literacy (Table 1) and high and low numeracy (Table 2). Notably, a higher proportion of individuals were less likely to be employed and less likely to have an adequate income in the low literacy and low numeracy groups. There is also a higher proportion of African-American individuals in the low numeracy group compared to the high numeracy group.

\section{Enrollment in Prevention Programs}

We hypothesized that the intervention effect would be stronger among Veterans with low literacy and numeracy as compared to those with high literacy and numeracy. Model results of enrollment in prevention programs provide some evidence that the intervention had a differential effect among high versus low numeracy Veterans (interaction term $p=0.05$ ), but not among high versus low literacy Veterans (interaction term $p=0.3$ ). As shown in Table 3, rates of enrollment were about $50 \%$ for all intervention patients, regardless of numeracy status. However, usual care enrollment rates were only $21 \%$ (95\% CI $0.14-0.30$ ) in the low numeracy subgroup versus $36 \%$ (95\% CI $0.28-0.46$ ) in the high numeracy subgroup, leading to the intervention having a greater effect on probability of enrollment in prevention programs for patients with low numeracy as compared to those with high numeracy $(0.18,95 \% \mathrm{CI}-0.01,0.38 ; p=0.07)$. There was no evidence of a significant interaction of literacy and numeracy upon enrollment in a prevention program $(p=0.60)$. The estimated probabilities show that the intervention has a significant effect upon enrollment for patients with low numeracy, regardless of literacy level.

\section{Patient Activation Scores}

Table 4 shows the estimated mean PAM scores with 95\% confidence intervals at 1-month and 6-month assessments for participants with high versus low numeracy and literacy. Participants with low numeracy exhibited the same changes in PAM scores regardless of intervention status with no differences in scores at 6 months (mean difference in improvement $0.15 ; 95 \% \mathrm{CI}-3.1,3.4)$. However, among patients with high numeracy, the intervention group had greater increases in PAM as compared to the control group at 6 months (mean difference in improvement 4.8; 95\% CI 1.7, 7.9; $p=0.003$ ), leading to a differential effect of the intervention for patients with low vs high numeracy $(-4.6 ; 95 \% \mathrm{CI}-9.1,-0.15 ; p=$ $0.04)$. There was no differential effect of the intervention on 
Table 1 Baseline Characteristics of Study Subjects for High Versus Low Literacy

\begin{tabular}{|c|c|c|c|c|c|}
\hline & \multirow{2}{*}{$\begin{array}{l}\text { Overall } \\
(n=417)\end{array}$} & \multicolumn{2}{|c|}{ High reading literacy } & \multicolumn{2}{|c|}{ Low reading literacy } \\
\hline & & $\begin{array}{l}\text { Intervention } \\
(n=148)\end{array}$ & $\begin{array}{l}\text { Usual care } \\
(n=144)\end{array}$ & $\begin{array}{l}\text { Intervention } \\
(n=60)\end{array}$ & $\begin{array}{l}\text { Usual care } \\
(n=65)\end{array}$ \\
\hline Age, mean (SD) & $55.8(12.2)$ & $54.2(13.2)$ & $55.1(12.8)$ & $57.9(11.1)$ & $58.9(8.2)$ \\
\hline \multicolumn{6}{|l|}{ Race, \% } \\
\hline African American & $169(40.5)$ & $62(41.9)$ & $53(36.8)$ & $28(46.7)$ & $26(40.0)$ \\
\hline Caucasian & $209(50.1)$ & $71(48.0)$ & $77(53.5)$ & $28(46.7)$ & $33(50.8)$ \\
\hline Other & $39(9.4)$ & $15(10.1)$ & $14(9.7)$ & $4(6.7)$ & $6(9.2)$ \\
\hline \multicolumn{6}{|l|}{ Ethnicity } \\
\hline Hispanic or Latino & $13(3.1)$ & $6(4.1)$ & $5(3.5)$ & $1(1.7)$ & $1(1.5)$ \\
\hline Married, \% & $213(51.1)$ & $60(40.5)$ & $80(55.6)$ & $36(60.0)$ & $37(56.9)$ \\
\hline Employed part/full time, \% & $153(36.7)$ & $62(41.9)$ & $54(37.5)$ & $17(28.3)$ & $20(30.8)$ \\
\hline Inadequate income, $\%$ & $111(26.6)$ & $38(25.7)$ & $35(24.3)$ & $19(31.7)$ & $19(29.2)$ \\
\hline General health excellent/very good, \% & $121(29.0)$ & $46(31.1)$ & $44(30.6)$ & $10(16.7)$ & $21(32.3)$ \\
\hline \multicolumn{6}{|l|}{ Study inclusion criteria met } \\
\hline $\mathrm{BMI} \geq 30, \%$ & $332(79.6)$ & $116(78.4)$ & $117(81.3)$ & $45(75.0)$ & $54(83.1)$ \\
\hline Physical activity $<150$ min per week, $\%$ & $209(50.1)$ & $71(48.0)$ & $74(51.4)$ & $28(46.7)$ & $36(55.4)$ \\
\hline Current cigarette smoker, $\%$ & $163(39.1)$ & $62(41.9)$ & $53(36.8)$ & $26(43.3)$ & $22(33.8)$ \\
\hline
\end{tabular}

PAM scores in Veterans with low versus high literacy (see Table 4). Results of the three-way interaction model approached statistical significance $(p=0.06)$, indicating that among patients with high numeracy and low literacy, PAM scores are significantly greater at 6 months for Veterans in the intervention group compared to Veterans in the control group (mean difference $=8.8,95 \%$ CI 3.0, 14.7).

\section{DISCUSSION}

In this secondary analysis of the ACTIVATE trial, we examined whether a health risk assessment and health coaching intervention resulted in similar increased enrollments in prevention programs and in patient activation among Veterans with low versus high literacy or numeracy.

Our results show that the intervention had a similar effect on enrollment in prevention programs regardless of baseline literacy. However, while not statistically significant, there was a clinically meaningful differential treatment effect in the low versus high numeracy groups, suggesting a larger effect of the intervention in the low numeracy group. What was particularly notable was the very low enrollment rate for patients with low numeracy in the control group, $21 \%$, when compared to all other groups. The most likely explanation for this finding is that by facilitating plain-language discussion of Veterans' health risks, the health coaching intervention relieved the burden of having to interpret numerical risk as presented by the HRA results. ${ }^{43}$ Interacting with a coach may have helped to put numeric values generated by the HRA into context and help make these values more meaningful. There is limited and inconsistent knowledge about the relationship between numeracy and the treatment decision-making process (e.g., choosing to enroll in a prevention program). ${ }^{44}$

The intervention also had a differential effect on patient activation scores between the low and high numeracy groups, but interestingly favored the high numeracy group

Table 2 Baseline Characteristics of Study Subjects for High Versus Low Numeracy

\begin{tabular}{|c|c|c|c|c|c|}
\hline & \multirow{2}{*}{$\begin{array}{l}\text { Overall } \\
(n=417)\end{array}$} & \multicolumn{2}{|c|}{ High numeric literacy } & \multicolumn{2}{|c|}{ Low numeric literacy } \\
\hline & & $\begin{array}{l}\text { Intervention } \\
(n=103)\end{array}$ & $\begin{array}{l}\text { Usual care } \\
(n=103)\end{array}$ & $\begin{array}{l}\text { Intervention } \\
(n=105)\end{array}$ & $\begin{array}{l}\text { Usual care } \\
(n=106)\end{array}$ \\
\hline Age, mean (SD) & $55.8(12.2)$ & $56.3(13.1)$ & $57.5(12.6)$ & $54.2(12.3)$ & $55.1(10.8)$ \\
\hline \multicolumn{6}{|l|}{ Race, \% } \\
\hline African American & $169(40.5)$ & $36(35.0)$ & $38(36.9)$ & $54(51.4)$ & $41(38.7)$ \\
\hline Caucasian & $209(50.1)$ & $57(55.3)$ & $54(52.4)$ & $42(40.0)$ & $56(52.8)$ \\
\hline Other & $39(9.4)$ & $10(9.7)$ & $11(10.7)$ & $9(8.6)$ & $9(8.5)$ \\
\hline \multicolumn{6}{|l|}{ Ethnicity, \% } \\
\hline Hispanic or Latino & $13(3.1)$ & $4(3.9)$ & $3(2.9)$ & $3(2.9)$ & $3(2.8)$ \\
\hline Married, \% & $213(51.1)$ & $48(46.6)$ & $58(56.3)$ & $48(45.7)$ & $59(55.7)$ \\
\hline Employed part/full time, \% & $153(36.7)$ & $43(41.7)$ & $44(42.7)$ & $36(34.3)$ & $30(28.3)$ \\
\hline Inadequate income, $\%$ & $111(26.6)$ & $21(20.4)$ & $24(23.3)$ & $36(34.3)$ & $30(28.3)$ \\
\hline General health excellent/very good, \% & $121(29.0)$ & $32(31.0)$ & $33(32.0)$ & $24(22.9)$ & $32(30.2)$ \\
\hline \multicolumn{6}{|l|}{ Study inclusion criteria met } \\
\hline $\mathrm{BMI} \geq 30, \%$ & $332(79.6)$ & $82(79.6)$ & $86(83.5)$ & $79(75.2)$ & $85(80.2)$ \\
\hline Physical activity $<150$ min per week, $\%$ & $209(50.1)$ & $43(41.7)$ & $51(49.5)$ & $56(53.3)$ & $59(55.7)$ \\
\hline Current cigarette smoker, $\%$ & $163(39.1)$ & $39(37.9)$ & $35(34.0)$ & $49(46.7)$ & $40(37.7)$ \\
\hline
\end{tabular}


Table 3 Predicted Probability of Enrollment in Prevention Programs for Participants According to Baseline Numeric and Reading Literacy Classification $(n=373)$

\begin{tabular}{cllll}
\hline \hline Group & $\begin{array}{l}\text { Intervention probability of } \\
\text { enrollment }(\mathbf{9 5 \%} \mathbf{C I})\end{array}$ & $\begin{array}{l}\text { Usual care probability of } \\
\text { enrollment } \mathbf{( 9 5 \%} \mathbf{C I})\end{array}$ & $\begin{array}{l}\text { Difference, intervention vs } \\
\text { usual care (95\% CI) }\end{array}$ & $\begin{array}{l}\text { Differential effect of intervention } \\
\text { (low vs high); } \boldsymbol{p} \text { value }\end{array}$ \\
\hline $\begin{array}{l}\text { Numeracy } \\
\text { Low }\end{array}$ & $0.52(0.42,0.63)$ & $0.21(0.14,0.30)$ & $0.31(0.18,0.45)$ & $0.18(-0.01,0.38) ; p=0.07$ \\
High & $0.50(0.39,0.60)$ & $0.36(0.28,0.46)$ & $0.13(-0.01,0.27)$ & \\
Literacy & & $0.23(0.15,0.35)$ & $0.29(0.12,0.46)$ & $0.11(-0.10,0.31) ; p=0.30$ \\
Low & $0.53(0.39,0.65)$ & $0.32(0.24,0.40)$ & $0.18(0.07,0.30)$ & \\
High & $0.50(0.41,0.59)$ & &
\end{tabular}

rather than the low numeracy group; and, in particular, the combined group of high numeracy and low literacy. There was no differential effect between the low versus high reading literacy groups alone. The exact reason for this is unclear. While reading and numeric literacy are known to be associated with patient activation, and health coaching has been shown to increase patient activation, there are no prior studies that specifically examine differential effects of health coaching on low reading or numeric literacy populations. ${ }^{14,} 15,31,45$ There is some data suggesting that patients with high numeric literacy are more likely and willing to engage in shared decision-making - it is possible then that the telephone calls with the coaches resulted in increased patient activation in this group. ${ }^{46}$

Nevertheless, the discrepancy noted between the results of enrollment in prevention programs and PAM scores raises the question of which factors aside from patient activation are contributing to the differential effects of health coaching on enrollment in patients with low numeracy. These factors may include changes in attitudes, knowledge, and patient-provider relationships and communication resulting from the health coaching intervention. Additionally, the subgroups included in this secondary analysis did have variability between them, including most notably, a lower rate of employment and adequate income in both the low literacy and low numeracy groups, and a higher proportion of African Americans in the low numeracy group.

This study has limitations. Our study was conducted in Veterans, and we have fewer female and Hispanic individuals than the general population. Additionally, the study was a secondary analysis. The original study was not designed to detect treatment differences in these subgroups, making these analyses underpowered to detect potentially clinically meaningful differences. Finally, the single-item assessment of literacy used in this study was shown to have a summary likelihood ratio of 2.9 (95\% CI 2.3-3.7) for inadequate or marginal literacy for answers of "sometimes" and more frequently, while answering "rarely" had a LR of 1.0 (95\% CI 0.81.3) ${ }^{37}$ In this study, participants who answered "rarely" were included in the low literacy subgroup, potentially resulting in a subgroup that did not consist entirely of individuals with inaccurate literacy and therefore minimizing a possible differential treatment effect.

The results of our study suggest that health coaching may be particularly beneficial in behavior change strategies in populations with low numeracy when interpretation of health risk

Table 4 Estimated Mean PAM and 95\% Confidence Intervals for Participants According to Baseline Numeric and Reading Literacy Classification $(n=417)$

\begin{tabular}{|c|c|c|c|c|}
\hline Time/group & Intervention (95\% CI) & Usual care $(95 \% \mathrm{CI})$ & $\begin{array}{l}\text { Difference, intervention vs usual care } \\
(95 \% \text { CI) }\end{array}$ & $\begin{array}{l}\text { Differential effect of intervention } \\
\text { (low vs high); } p \text { value }\end{array}$ \\
\hline \multicolumn{5}{|l|}{ Numeracy } \\
\hline \multicolumn{5}{|l|}{ Baseline* } \\
\hline Low & $59.2(57.6,60.9)$ & $59.2(57.6,60.9)$ & & \\
\hline High & $63.9(62.2,65.6)$ & $63.9(62.2,65.6)$ & & \\
\hline \multicolumn{5}{|l|}{ Week 6} \\
\hline Low & $61.0(58.6,63.5)$ & $60.9(58.6,63.3)$ & $0.07(-3.2,3.3)$ & $-2.8(-7.3,1.7) ; p=0.22$ \\
\hline High & $65.4(63.0,67.8)$ & $62.6(60.2,64.9)$ & $2.9(-0.3,6.0)$ & \\
\hline \multicolumn{5}{|l|}{ Month 6} \\
\hline Low & $63.9(61.4,66.4)$ & $63.7(61.4,66.1)$ & $0.15(-3.1,3.4)$ & $-4.6(-9.1,-0.15) ; p=0.04$ \\
\hline High & $68.8(66.4,71.2)$ & $64.0(61.6,66.4)$ & $4.8(1.7,7.9)$ & \\
\hline \multicolumn{5}{|l|}{ Literacy } \\
\hline \multicolumn{5}{|l|}{ Baseline* } \\
\hline Low & $57.4(55.2,59.5)$ & $57.4(55.2,59.5)$ & & \\
\hline High & $63.3(61.9,64.7)$ & $63.3(61.9,64.7)$ & & \\
\hline \multicolumn{5}{|l|}{ Week 6} \\
\hline Low & $60.3(57.2,63.5)$ & $58.6(55.7,61.5)$ & $1.7(-2.3,5.8)$ & $0.4(-4.5,5.2) ; p=0.89$ \\
\hline High & $64.5(62.4,66.6)$ & $63.1(61.2,65.1)$ & $1.4(-1.4,4.1)$ & \\
\hline \multicolumn{5}{|l|}{ Month 6} \\
\hline Low & $63.6(60.4,66.8)$ & $60.6(57.7,63.6)$ & $3.0(-1.1,7.0)$ & $0.7(-4.1,5.5) ; p=0.78$ \\
\hline High & $67.5(65.5,69.6)$ & $65.3(63.2,67.3)$ & $2.3(-0.4,5.0)$ & \\
\hline
\end{tabular}

*As recommended for the analysis of randomized trials ${ }^{42}$ to improve efficiency, the longitudinal model constrained the intercept to be the same for intervention and usual care groups 
information is part of the intervention. The health coaching intervention resulted in overall higher rates of enrollment in prevention programs, regardless of health literacy level; however, the differential effect of health coaching on the low versus high numeracy subgroups highlights that health coaching may also reduce disparate effects of certain health behavior interventions on populations with low health literacy. Additionally, our findings that PAM scores improved significantly for patients with high numeracy underscores that this group may be more activated by a health coaching intervention grounded in motivational interviewing. These findings demonstrate the need for further examination of health coaching as a strategy for reducing inequities in health and in motivations for behavior change. Furthermore, coaching strategies that are tailored to populations with low health literacy - for example, using plain language and incorporating graphical methods of risk communication-may potentially result in more significant treatment effects. Our results also illustrate that the relationship between health literacy, patient activation, and behavior change is complex and likely requires multilevel interventions that consider interpersonal, community, and policy in addition to individual-level interventions such as health coaching. ${ }^{47}$

Acknowledgments: We are grateful to the leadership and staff of the VA's National Center of Health Promotion and Disease Prevention (NCP) for the constant support throughout this project, including Dr. Jane Kim, Chief Consultant (NCP) and Ms. Kathleen Pitman. We also acknowledge the dedication and professionalism of our two health coaches, Ms. Karen Juntilla and Ms. Courtney White-Clark.

Corresponding Author: Sarah S. Nouri, M.D., M.P.H.; Division of General Internal Medicine, Department of Medicine University of California, San Francisco, CA, USA (e-mail: sarah.nouri@ucsf.edu).

Funding Information This project was funded by the Department of Veterans Affairs, Health Services Research and Development Service (CRE 12-288) and by a fellowship training grant by the National Research Service Award (NRSA) T32HP19025.

\section{Compliance with Ethical Standards:}

Conflict of Interest: The authors declare that they do not have a conflict of interest.

Publisher's Note: Springer Nature remains neutral with regard to jurisdictional claims in published maps and institutional affiliations.

\section{REFERENCES}

1. Hibbard JH, Mahoney ER, Stockard J, Tusler M. Development and testing of a short form of the patient activation measure. Health Serv Res 2005;40:1918-1930.

2. Greene $\mathbf{J}$ and Hibbard $\mathbf{J H}$. Why does patient activation matter? An examination of the relationships between patient activation and health related outcomes. J Gen Intern Med. 2012;27(5):520-26.

3. Sontag U, Wiesner J, Fahrenkrog S, Renneberg B, Braun V, Heintze C Motivational interviewing and shared decision making in primary care. Pat Educ Couns. 2012;87(1):62-6.

4. Harvey L, Fowles JB, Xi M, Terry P. When activation changes, what else changes? The relationship between change in patient activation measure (PAM) and employees' health status and health behaviors. Patient Educ Couns. 2012;88(2):338-43.
5. Hendren S, Griggs JJ, Epstein RM, et al. Study protocol: a randomized controlled trial of patient nativation-activation to reduce cancer health disparities. BMC Cancer. 2010;10:551

6. Hill B, Richardson B, Skouteris H. Do we know how to design effective health coaching interventions: a systematic review of the state of the literature. Am J Health Promot. 2015;29(5):158-68.

7. Bosworth HB, Olsen MK, Grubber JM, et al. Two self-management interventions to improve hypertension control: a randomized trial. Ann Intern Med. 2009;151(10):687-95.

8. Bosworth HB, Olsen MK, Dudley T, et al. Patient education and provider decision support to control blood pressure in primary care: a cluster randomized trial. Amer Heart J. 2009;157(3):450-6.

9. Damschroder LJ, Lutes LD, Goodrich DE, Gillon L, Lowery JC. A small-change approach delivered via telephone promotes weight loss in Veterans: Results from the ASPIRE-VA pilot study. Patient Educ Couns. 2010;79(2): 262-6.

10. Eakin EG, Lawler SP, Vandelanotte C, Owen N. Telephone interventions for physical activity and dietary behavior change: a systematic review. Am J Prev Med. 2007;32(5):419-434.

11. Alexander JA, Hearld LR, Mittler JN, Harvey J. Patient-physician role relationships and patient activation among individuals with chronic illness. Health Serv Res. 2012;47(3): 1201-23.

12. Cunningham PJ, Hibbard J, Gibbons CB. Raising low 'patient activation' rates among Hispanic immigrants may equal expanded coverage in reducing access disparities. Health Aff. 2011;30(10):1888-94

13. Hibbard $\mathbf{J H}$ and Cunningham PJ. How engaged are consumers in their health and health care, and why does it matter? Res Brief. 2009;8:1-9.

14. Martin LT, Schonlau M, Haas A, et al. Patient Activation and Advocacy: Which Literacy Skills Matter Most? J Health Commun. 2011;16(3):177190.

15. Smith SG, Curtis LM, Wardle J, von Wagner C, Wolf MS. Skill set or mind set? Associations between health literacy, patient activation and health. PLoS One. 2013;8(9): e74373.

16. Eneanya ND, Winter M, Cabral H, et al. Health literacy and education as mediators of racial disparities in patient activation within an elderly patient cohort. J Health Care Poor Underserved. 2016;27(3):1427-40.

17. Gwynn KB, Winter MR, Cabral HJ, et al. Racial disparities in patient activation: evaluating the mediating role of health literacy with path analyses. Patient Educ Couns. 2016;99(6):1033-7.

18. Institute of Medicine (US) Committee on Health Literacy. Health literacy: a prescription to end confusion. Washington, D.C: National Academies Press; 2004.

19. Kirsch IS, Jungeblut A, Jenkins L, Kolstad A. Adult literacy in America: a first look at the findings of the National Adult Literacy Survey (NALS). Washington, DC: U.S. Department of Education, National Center for Education Statistics; 1993.

20. Kutner M, Greenberg E, Baer J. A first look at the literacy of America's adults in the 21st century. Washington, DC: U.S. Department of Education, National Center for Education Statistics; 2005.

21. Goodman M, Finnegan R, Mohadjer L, Krenzke T, Hogan J. Literacy, numeracy, and problem solving in technology-rich environments among U.S. adults: Results from the program for the international assessment of adult compe- tencies 2012: First look (NCES 2014-008). Washington, DC: U.S. Department of Education, National Center for Education Statistics; 2013.

22. OECD. OECD skills outlook 2013: first results from the survey of adult skills. OECD Publishing; 2013, http://www.oecd-ilibrary.org/education/ oecd-skills-outlook-2013_9789264204256-en. Accessed May 2017.

23. Berkman ND, Sheridan SL, Donahue KE, Halpern DJ, Crotty K. Low health literacy and health outcomes: an updated systematic review. Ann Intern Med. 2011;155(2):97-107.

24. Baker DW, Wolf MS, Feinglass J, Thompson JA, Gazmararian JA, Huang $\mathbf{J}$. Health literacy and mortality among elderly persons. Arch Intern Med. 2007; 167:1503-9.

25. Nelson W, Reyna VF, Fagerlin A, Lipkus I, Peters E. Clinical Implications of Numeracy: Theory and Practice. Ann Behav Med. 2008;35(3):261-274

26. Wu JR, Moser DK, DeWalt DA, Rayens MK, Dracup K. Health literacy mediates the relationship between age and health outcomes in patients with heart failure. Circ Heart Fail. 2016;9(1):e002250.

27. Gazmararian JA, Baker DW, Williams MV, Parker RM, Scott TL, Green DC, et al. Health literacy among Medicare enrollees in a managed care organization. JAMA. 1999;10(28):545-51.

28. Bennett IM, Chen J, Soroui JS, White S. The contribution of health literacy to disparities in self-rated health status and preventive health behaviors in older adults. Ann Fam Med. 2009;7:204-11. 
29. Howard DH, Sentell T, Gazmararian JA. Impact of health literacy on socioeconomic and racial differences in health in an elderly population. $J$ Gen Intern Med. 2006;21:857-61.

30. Sentell TL, Halpin HA. Importance of adult literacy in understanding health disparities. J Gen Intern Med. 2006;21:862-6.

31. Oddone EZ, Damschroder LJ, Gierisch JM, et.al. A Coaching by Telephone Intervention on Engaging Patients to Address Modifiable Cardiovascular Risk Factors: A Randomized Controlled Trial. J Gen Intern Med, 2018 (in press).

32. Oddone EZ, Damschroder LJ, Gierisch J, et al.. A Coaching by Telephone Intervention for Veterans and Care Team Engagement (ACTIVATE): A study protocol for a Hybrid Type I effectiveness-implementation randomized controlled trial. Contemp Clin Trials. 2017;55:1-9.

33. Veterans Health Administration. MyHealtheVet: HealtheLiving Assessment <https://www.myhealth.va.gov/mhv-portal-web/web/ myhealthevet/ss20170509-birds-eye-view-of-your-wellness-and-yourhealth-risks>. Accessed May 2017

34. Hibbard JH, Mahoney E R, Stock R, Tusler M (2007). Do increases in patient activation result in improved self-management behaviors? Health Serv Res 2007; 42(4): 1443-1463.

35. Remmers C, Hibbard J, Mosen DM, Wagenfield M, Hoye RE, Jones C Is patient activation associated with future health outcomes and healthcare utilization among patients with diabetes? J Ambulatory Care Manage 2009;32:320-327.

36. Chew LD, Griffin JM, Partin MR, et al. Validation of screening questions for limited health literacy in a large VA outpatient population. J Gen Intern Med. 2008;23(5):561-6.

37. Powers, BJ, Trinh JV, Bosworth HB. Can this patient read and understand written health information? JAMA. 2010;34(1):76-84.
38. Chew LD, Bradley KA, Boyko EJ. Brief questions to identify patients with inadequate health literacy. Fam Med 2004;36(8):588-94.

39. Zikmund-Fisher BJ, Smith DM, Ubel PA, Fagerlin A. Validation of the Subjective Numeracy Scale: effects of low numeracy on comprehension of risk communications and utility elicitations. Med Decis Making. 2007;27(5):663-71.

40. Fagerlin A, Zikmund-Fisher BJ, Ubel PA, Jankovic A, Derry HA, Smith DM. Measuring numeracy without a math test: development of the Subjective Numeracy Scale. Med Decis Making. 2007;27(5):672-80.

41. McNaughton CD, Cavanaugh KL, Kripalani S, Rothman RL, Wallston KA. Validation of a Short, 3-Item Version of the Subjective Numeracy Scale. Med Decis Making. 2015;35(8):932-6.

42. Fitzmaurice, GM, Laird NM, and Ware JH. Applied longitudinal analysis. Vol. 998. Hoboken NJ: John Wiley \& Sons, 2012.

43. Fagerlin A, Zikmund-Fisher BJ, Ubel PA. Helping patients decide: Ten steps to better risk communication. JNCI. 2011;103(19): 1436-1443.

44. Malloy-Weir LJ, Schwartz L, Yost J, McKibbon KA. Empirical relationships between numeracy and treatment decision making: A scoping review of the literature. Pat Educ Couns. 2016;99(3):310-325.

45. Lawson KL, Jonk Y, O'Connor H, Riise KS, Eisenberg DM, Kreitzer MJ. The impact of telephonic health coaching on health outcomes in a high-risk population. Glob Adv Health Med. 2013;2(3):40-47.

46. Galesic $\mathbf{M}$ and Garcia-Retamero $\mathbf{R}$. Do low-numeracy people avoid shared decision making? Health Psychol. 2011;30(3):336-341.

47. McCormack L, Thomas V, Lewis MA, Rudd R. Improving low health literacy and patient engagement: A social ecological approach. Pat Educ Couns. 2017;100(1):8-13. 